\title{
Impact of RGS2 deficiency on the therapeutic effect of telmisartan in angiotensin II-induced aortic aneurysm
}

\author{
Sachiko Matsumoto ${ }^{1}$, Kei Kamide ${ }^{1,2}$, Fumiaki Banno ${ }^{1}$, Nobutaka Inoue ${ }^{1,3}$, Naoki Mochizuki ${ }^{1}$, Yuhei Kawano ${ }^{4}$ \\ and Toshiyuki Miyata ${ }^{1}$
}

Regulator of G-protein signaling 2 (RGS2) negatively regulates the signaling of G-protein-coupled receptors, such as the angiotensin II (AngII) type 1 receptor by accelerating the inactivation of Gaq. Rgs2-deficient mice show increased sensitivity and prolonged responsiveness to vasoconstrictors, and genetic variations in the RGS2 gene are associated with hypertension in humans. This study aimed to clarify whether Rgs2 deficiency contributes to the development of vascular remodeling and therapeutic efficacy of the angiotensin receptor blocker telmisartan on atherosclerotic vascular damage. We treated $\mathrm{Rgs}^{+/+}$,

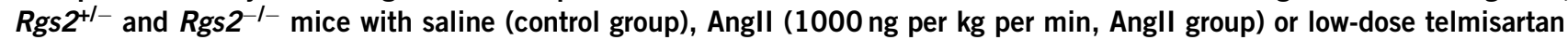
( $0.3 \mathrm{mg}$ per kg per day) with Angll infusion (Angll+Telmi group) for 4 weeks. For all genotypes, the Angll groups exhibited significantly higher blood pressure, a higher mortality rate and a higher incidence of aortic aneurysm than the respective control group. Interestingly, aneurysm incidence was decreased in the Angll+Telmi group compared with the Angll group in Rgs $2^{-1-}$ mice (6.7 vs. $42.9 \%, P<0.05$ ), but not in $R g s 2^{+/+}$mice (38.9 vs. $40.0 \%$ ). Moreover, in Rgs $2^{-1-}$ mice, the Angll+Telmi group exhibited significant improvement in survival, reduction of enlarged aortic diameter, inhibition of superoxide production and suppression of $\mathrm{NAD}(\mathrm{P}) \mathrm{H}$ oxidase activity compared with the Angll group. Thus, Rgs2 deficiency potentiates the vascular protection effect of low-dose telmisartan. Our results suggest that angiotensin receptor blocker may be useful for protection from cardiovascular events in hypertensive subjects with risk alleles in the RGS2 gene.

Hypertension Research (2010) 33, 1244-1249; doi:10.1038/hr.2010.184; published online 30 September 2010

Keywords: angiotensin II; aortic aneurysm; oxidative stress; RGS2; telmisartan

\section{INTRODUCTION}

The renin-angiotensin system has an important role in the regulation of blood pressure and vascular structure. Angiotensin II (AngII) is a potent vasoconstrictor that elevates blood pressure through a G-protein-coupled receptor, angiotensin type 1 receptor (AT1R). AngII generates aldosterone at the adrenal gland and activates the sympathetic nervous system, leading to blood pressure elevation. In addition to the effects of AngII on the elevation of blood pressure, evidence has revealed that it has a role in atherogenesis. In animal models, chronic infusion of AngII promotes the formation of atherosclerotic lesions and aneurysms. ${ }^{1,2}$ It is widely known that AngII-induced $\mathrm{NAD}(\mathrm{P}) \mathrm{H}$ oxidase activation increases the production of reactive oxygen species from various cell types, ${ }^{3}$ including endothelial cells, vascular smooth muscle cells and monocytes/macropharges, and promotes inflammation in atherosclerotic lesions. ${ }^{4}$

Regulator of G-protein signaling 2 (RGS2) is present in many cardiovascular tissues, including the heart, kidney and blood vessels, and it is required for normal vascular function and regulation of blood pressure. $^{5}$ RGS2 negatively regulates the signaling of G-protein- coupled receptors, such as $\mathrm{AT}_{1} \mathrm{R}$, by accelerating the inactivation of G $\alpha$ by its guanosine triphosphatase-activating protein activity. RGS2 also mediates the nitric oxide-cyclic guanosine monophosphate pathway to decrease vascular resistance and attenuate vasoconstrictor signaling in vascular smooth muscle cells. ${ }^{5,6}$ Patients with Bartter's and Gitelman's syndromes have hypotension with an enhancement of RGS2 expression. ${ }^{7}$ Taken together, silencing of the RGS2 gene disrupts these pathways and enhances the vasoconstrictor signaling.

The first reported phenotypes of Rgs2-deficient mice were the reduction of T-cell activation, the control of synapse development in the hippocampus and an increase in anxiety responses. ${ }^{8}$ With respect to the blood pressure regulation, Rgs2-deficient mice exhibit a hypertensive phenotype and persistent constriction of the resistance vasculature. ${ }^{5,9}$ This hypertensive phenotype differs in degree according to conditions such as age in weeks, anesthesia, postoperative recovery, restrained stress, time zone and apparatus for blood pressure measurement. ${ }^{5,9,10}$ Together with another group, we have reported that genetic polymorphisms within the human RGS2 gene are associated with hypertension. ${ }^{11-14}$ It has been speculated that genetic variations

${ }^{1}$ Research Institute, National Cerebral and Cardiovascular Center, Suita, Osaka, Japan; ${ }^{2}$ Department of Geriatric Medicine and Nephrology, Osaka University Graduate School of Medicine, Suita, Osaka, Japan; ${ }^{3}$ Department of Cardiovascular Medicine, Kobe Rosai Hospital, Kobe, Hyogo, Japan and ${ }^{4}$ Division of Hypertension and Nephrology, National Cerebral and Cardiovascular Center, Suita, Osaka, Japan

Correspondence: Dr K Kamide, Department of Geriatric Medicine and Nephrology, Osaka University Graduate School of Medicine, 2-2, Yamadaoka, Suita city, Osaka 565-0871, Japan.

E-mail: kamide@geriat.med.osaka-u.ac.jp

Received 28 May 2010; revised 21 June 2010; accepted 28 June 2010; published online 30 September 2010 
may reduce RGS2 function. ${ }^{15,16}$ Because hypertension contributes to the pathogenesis of cardiovascular disease, it is hypothesized that genetic variations in RGS2 might be a risk factor for the development of atherosclerosis through enhancement of AngII signaling.

Telmisartan is an angiotensin receptor blocker (ARB) with a longer half-life and higher lipophilicity than other $\mathrm{ARBs},{ }^{17}$ and it is a commonly used medication for the treatment of hypertension. In a recent clinical trial, ${ }^{18,19}$ telmisartan resulted in the prevention of vascular events such as myocardial infarction and stroke. Therefore, telmisartan is expected to be effective for cardiovascular protection in Rgs2-deficient mice that have enhanced AngII signaling.

In this study, we investigated the effects of RGS2 deficiency on the development of vascular remodeling and the therapeutic efficacy of low-dose telmisartan on atherosclerotic vascular damage resulting from excessive stimulation of $\mathrm{AT}_{1} \mathrm{R}$ by RGS2 deficiency.

\section{METHODS}

\section{Mice}

Rgs2-deficient mice on the C57BL/6 background were provided by Dr Michael E Mendelsohn (Tufts University School of Medicine). ${ }^{8}$ Mice were kept in a specific pathogen-free barrier under constant temperature conditions and housed on a 12-h light/12 h dark cycle. All experiments were approved by the Animal Care and Use Committees of the National Cardiovascular Center, Japan, and they were performed in accordance with the guidelines.

\section{Drug administration}

We used 18-week old male Rgs2-deficient $\left(\mathrm{Rgs}^{-1-}, \mathrm{Rgs}^{+/-}\right)$and wild-type $\left(\mathrm{Rgs}^{+/+}\right)$mice and divided them into three treatment groups. Mice were subcutaneously infused with AngII (1000 ng per kg per min, AngII group), or saline containing $0.3 \%$ bovine serum albumin (control group) using an ALZET Micro-Osmotic Pump (model 1004, Durect, Cupertino, CA, USA) for 4 weeks. Mice were also treated with AngII (1000 ng per kg per min) and low-dose telmisartan ( $0.3 \mathrm{mg}$ per $\mathrm{kg}$ per day, AngII+Telmi group). Telmisartan was administered in drinking water. We adopted a low dosage of telmisartan that does not affect blood pressure. ${ }^{20}$

\section{Hemodynamic analysis}

Systolic blood pressure and heart rate were measured in conscious, prewarmed, and restrained mice by the tail-cuff method using a non-invasive blood pressure measuring device (BP98-A, Softron, Tokyo, Japan) before treatment and on days 7, 14, 21 and 28 after treatment just around the same time of day. For stable measurement, tail-cuff pressures were obtained after a 2week-training period to acclimatize the mice to the restraining device and cuff inflation. The pulse waveform was monitored in real time using the BP98AW software (version 2.12, Softron). The first 10 measurements were excluded from the analysis, and at least 5 measurements with an untroubled pulse waveform were collected.

\section{Biochemical examination}

After 4 weeks of treatment, overnight fasting blood was collected from anesthetized mice and put into capillary blood collection tubes including a gel/clot activator (Capiject tube, Terumo Medical, Somerset, NJ, USA). Serum was obtained by the manufacturer's instructions and stored at $-80^{\circ} \mathrm{C}$ in aliquots before use. Serum levels of blood urea nitrogen, creatinine, aspartate aminotransferase, alanine aminotransferase, lactate dehydrogenase, low-density lipoprotein-cholesterol and glucose were measured using a Hitachi clinical analyzer (model 7180, Hitachi High-Technologies, Tokyo, Japan).

\section{Aortic tissue collection and morphometric analysis}

Dissection was performed under anesthesia after blood collection. After thoracolaparotomy, the inferior vena cava was cut for exsanguination and the aorta was perfused with ice-cold saline through the left ventricle. The aortic root and heart were subsequently eviscerated, and the periadventitial tissue was dissected away under a stereomicroscope. The external diameters in the middle of the suprarenal abdominal aorta between the diaphragm and renal artery bifurcation were measured using the ImageJ software (version 1.40, National Institute of Health, Bethesda, MD, USA). After taking the images, the aorta was cut into thoracic and abdominal regions. The thoracic aorta was immediately frozen by liquid nitrogen and stored at $-80^{\circ} \mathrm{C}$ for the measurement of $\mathrm{NAD}(\mathrm{P}) \mathrm{H}$ oxidase activity. The suprarenal abdominal aorta was cut into two pieces. For detection of superoxide production, the superior half was immediately embedded in OCT compound (Sakura Finetek Japan, Tokyo, Japan) in liquid nitrogen and stored at $-80^{\circ} \mathrm{C}$. For immunohistochemical staining, the inferior half was fixed with $4 \%$ paraformaldehyde overnight and paraffin embedded.

\section{Detection of aortic superoxide production}

Aortic superoxide levels were measured with dihydroethidium (Invitrogen Molecular Probes, Carlsbad, CA, USA) on cross sections $(9 \mu \mathrm{m})$ obtained from the unfixed frozen blocks of abdominal aorta, as previously described. ${ }^{21}$ The unfixed frozen sections were stained by dihydroethidium $\left(2 \mu \mathrm{M}, 30 \mathrm{~min}, 37^{\circ} \mathrm{C}\right)$ in a dark humidified chamber and washed briefly. The images were captured with a laser scanning confocal fluorescent microscope (FLUOVIEW system, Olympus, Tokyo, Japan). For the quantification of ethidium fluorescence, the mean fluorescence intensity (fluorescence intensity per unit area) in the aortic wall was calculated using the ImageJ software on high-power (x300) images.

\section{Measurement of $\mathrm{NAD}(\mathrm{P}) \mathrm{H}$ oxidase activity}

The frozen aortic segments were homogenized using a Sample Grinding Kit (GE Healthcare UK, Buckinghamshire, England). After centrifugation, the supernatant was stored at $-80^{\circ} \mathrm{C}$ until use. Protein concentrations were measured by the BCA protein assay kit (Pierce Biotechnology, Rockford, IL, USA). The enzymatic activity of $\mathrm{NAD}(\mathrm{P}) \mathrm{H}$ oxidase of the homogenates was measured by lucigenin-enhanced chemiluminescence, as previously described. ${ }^{20}$ The assay solution contained lucigenin $(250 \mu \mathrm{M})$ as an electron acceptor and $\mathrm{NADH}(100 \mu \mathrm{M})$ or NADPH $(100 \mu \mathrm{M})$ as a substrate. After pre-incubation at $37^{\circ} \mathrm{C}$ for $20 \mathrm{~min}$, the reaction was started by adding $50 \mu \mathrm{g}$ of homogenate. Photon emissions were continuously recorded for $15 \mathrm{~min}$ with a chemiluminescence reader (BLR-201, ALOKA, Tokyo, Japan). The chemiluminescent signals observed in the absence of homogenates were subtracted from the signals of the samples. The signal was corrected for the protein concentration of each homogenate and expressed as counts per minute by $\mathrm{mg}$ protein for a 15min period. In some experiments, the homogenates were pre-incubated with $10 \mu \mathrm{M}$ diphenyleneiodium, a selective NADPH oxidase inhibitor, for $20 \mathrm{~min}$ before the lucigenin-enhanced chemiluminescence measurements.

\section{Statistical analysis}

Data are expressed as mean \pm s.e.m. All statistical analyses were performed using the Prism software (version 5.0, GraphPad Software, La Jolla, CA, USA). Hemodynamic changes were analyzed by two-way analysis of variance during the period of administration. Differences between multiple groups were analyzed by one-way analysis of variance or Kruskal-Wallis test in the case of a non-Gaussian distribution, followed by the Bonferroni post-hoc test for comparison between treatment groups or genotype groups. The log-rank (Mantel-Cox) test was used for statistical analysis of survival curves, and the $\chi^{2}$-test was used to compare the incidence of aneurysm. Values of $P<0.05$ were considered statistically significant.

\section{RESULTS}

\section{Changes in blood pressure}

To elucidate the direct role of AngII signaling in Rgs2-deficient mice, we divided $\mathrm{Rgs2^{+/+ }}, \mathrm{Rgs2^{+/- }}$ and $\mathrm{Rgs} \mathrm{2}^{-/-}$mice into three treatment groups: the control group, the AngII group and the AngII+Telmi group. Drug administration was performed for 4 weeks, and hemodynamic changes were measured. In all Rgs2 genotypes, the AngII group exhibited $\sim 50 \mathrm{~mm} \mathrm{Hg}$ higher systolic blood pressure than the control group $(P<0.001)$ (Figure 1$)$. Rgs 2 dysfunction was expected to enhance the AngII signaling, leading to higher blood pressure in 


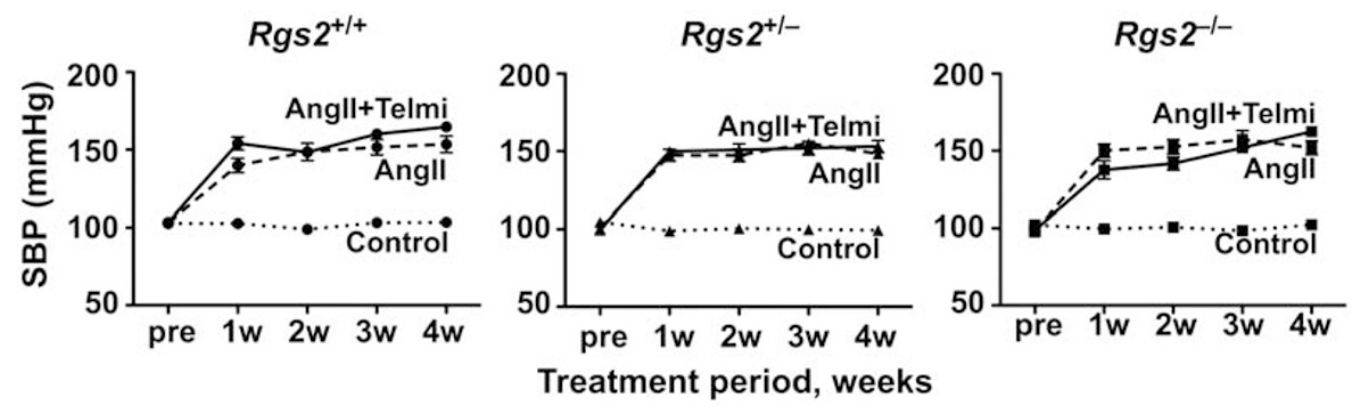

Figure 1 Blood pressure changes in response to Angll or Angll plus telmisartan. Systolic blood pressure (SBP) variations were shown in Rgs $2^{+/+}$, Rgs $^{+/-}$ and Rgs $^{-1-}$ mice. Mice were divided into three groups, control group (saline), Angll group (Angll, $1000 \mathrm{ng}$ per kg per min) and Angll+Telmi group (Angll, $1000 \mathrm{ng}$ per $\mathrm{kg}$ per min, telmisartan, $0.3 \mathrm{mg}$ per $\mathrm{kg}$ per day). Results are expressed as mean \pm s.e.m. in the control group $\left(R g s 2^{+/+}: n=8, R g s 2^{+/-}: n=8\right.$,

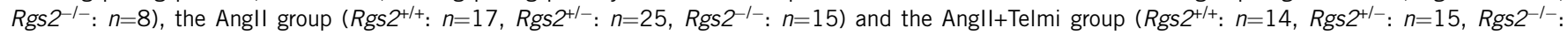
$n=15)$. The AngII and AngII+Telmi groups showed significantly higher SBP than the control group $(P<0.001)$.
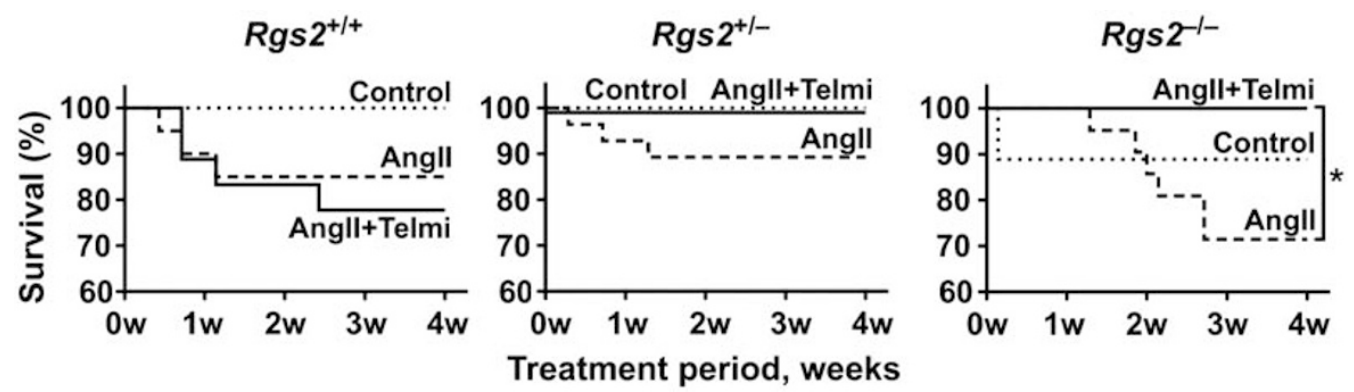

Figure 2 Comparison of survival curves in mice treated with Angll or Angll plus telmisartan. The treatment design was the same as that in Figure 1. The

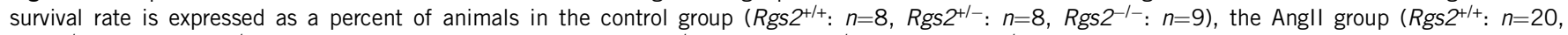

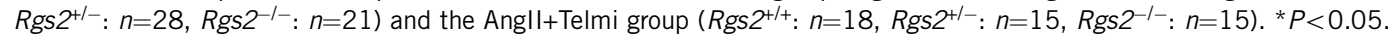

$R g s 2^{-1-}$ mice, but there were no blood pressure differences among the Rgs2 genotypes in the AngII group. Moreover, the AngII+Telmi group did not show reduced blood pressure in any of the genotypes. Before drug administration, there were no significant differences in blood pressure among the Rgs2 genotypes in our experimental condition using the tail-cuff method. Both the AngII and the AngII+Telmi groups showed no differences in heart rate among the genotypes (data not shown). Although $R g s 2^{-1-}$ mice tended to show a lower body weight than the other genotypes, drug administration did not affect the body weight (data not shown).

Survival rates and blood biochemical examinations

Some mice died during the period of administration mainly because of the cardiovascular events, including the rupture of aneurysms. Therefore, we compared the survival curves in mice with all Rgs2 genotypes and with the three treatment groups. As shown in Figure 2, AngII treatment decreased the survival rate for all the Rgs2 genotypes compared with the control group, but there were no significant differences in survival rate among the Rgs2 genotypes in the AngII group. Interestingly, Rgs $2^{-1-}$ mice treated with AngII+Telmi had significantly improved survival compared with $\mathrm{Rgs} 2^{-1-}$ mice treated with AngII alone $(P<0.05)$.

As shown in the Table 1, blood urea nitrogen levels were significantly increased in the AngII and AngII+Telmi groups compared with the control group $(P<0.05)$. Creatinine levels also tended to increase in the AngII group compared with the control group. These results indicated the exacerbation of renal function caused by AngII-induced
Table 1 Biochemical examinations of serum samples

\begin{tabular}{|c|c|c|c|c|}
\hline & Rgs2 & Control & Angll & Angll+Telmi \\
\hline \multirow[t]{3}{*}{ BUN (mg dl $\left.{ }^{-1}\right)$} & $+/+$ & $27.2 \pm 2.9$ & $57.1 \pm 4.6^{*}$ & $51.7 \pm 1.8^{*}$ \\
\hline & $+1-$ & $23.8 \pm 1.9$ & $52.7 \pm 2.2^{*}$ & $48.8 \pm 3.7^{*}$ \\
\hline & $-1-$ & $29.4 \pm 4.3$ & $47.8 \pm 2.3^{*}$ & $51.0 \pm 2.6^{*}$ \\
\hline \multirow[t]{3}{*}{ CRE (mg dl $\left.{ }^{-1}\right)$} & +/+ & $0.07 \pm 0.00$ & $0.12 \pm 0.01 *$ & $0.09 \pm 0.01$ * \\
\hline & $+/-$ & $0.06 \pm 0.01$ & $0.13 \pm 0.01$ * & $0.10 \pm 0.01 *$ \\
\hline & $-1-$ & $0.06 \pm 0.01$ & $0.10 \pm 0.01$ & $0.08 \pm 0.01$ \\
\hline \multirow[t]{3}{*}{ LDL-C (mg dl $\left.{ }^{-1}\right)$} & $+/+$ & $2.0 \pm 0.0$ & $3.1 \pm 0.3$ & $4.9 \pm 0.7$ \\
\hline & $+1-$ & $2.4 \pm 0.4$ & $4.1 \pm 0.4$ & $2.8 \pm 0.3$ \\
\hline & $-1-$ & $5.0 \pm 1.2$ & $6.0 \pm 1.4$ & $3.1 \pm 0.5^{\dagger}$ \\
\hline \multirow[t]{3}{*}{$\mathrm{GLU}\left(\mathrm{mg} \mathrm{dl}^{-1}\right)$} & $+/+$ & $108.4 \pm 14.4$ & $93.6 \pm 11.7$ & $98.6 \pm 14.1$ \\
\hline & $+/-$ & $112.4 \pm 23.8$ & $103.5 \pm 10.4$ & $109.5 \pm 10.7$ \\
\hline & $-1-$ & $70.8 \pm 7.2$ & $72.2 \pm 9.7$ & $88.9 \pm 8.1$ \\
\hline
\end{tabular}

Abbreviations: AngII, angiotension II; BUN, blood urea nitrogen; CRE, creatinine, LDL-C, lowdensity lipoprotein-cholesterol; GLU, glucose, Rgs2, regulator of G-protein signaling 2; Telmi, telmisartan.

Results are expressed as mean \pm s.e.m. in the control group $\left(R g s 2^{+++}: n=5, R g s 2^{+1-}: n=5\right.$,

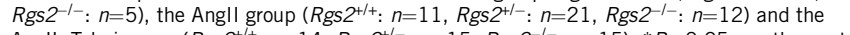
Angll+Telmi group (Rgs2 ${ }^{+++}: n=14$, Rgs $2^{+-}: n=15$, Rgs $\left.2^{-1-}: n=15\right) .{ }^{*} P<0.05$, vs. the control group. ${ }^{\dagger} P<0.05$, vs. the Angll group.

hypertension in all Rgs2 genotypes. Recent studies have shown that telmisartan improves the metabolism of lipids and glucose. ${ }^{22,23}$ Our study showed that low-density lipoprotein-cholesterol levels were significantly decreased in the AngII+Telmi group compared with the 
a

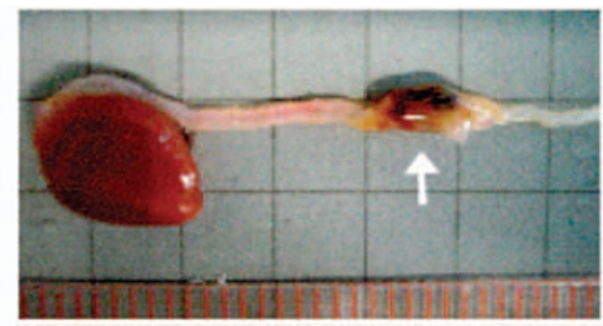

b
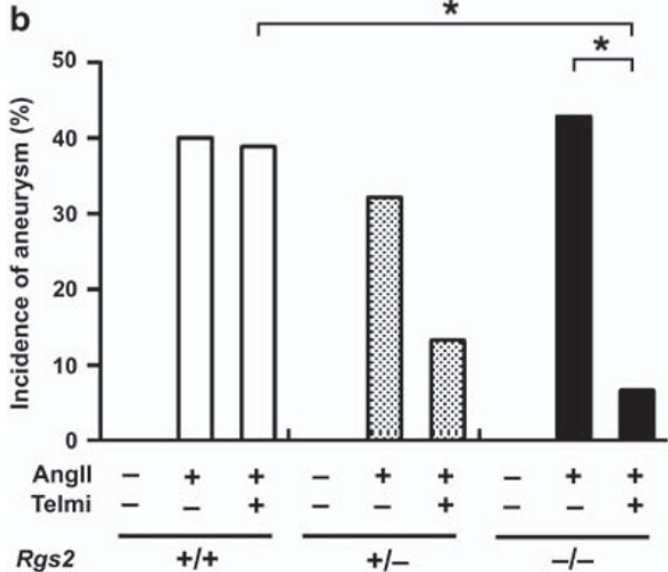

Figure 3 Gross morphology and incidence of aortic aneurysms observed in mice treated with Angll or Angll plus telmisartan. (a) Representative photograph showing the macroscopic features of aneurysm induced by Angll treatment. Aneurysm is indicated by arrow. (b) The incidence of aneurysms is expressed as a percent of animals in the control group $\left(\operatorname{Rgs}^{+/+}: n=8\right.$,

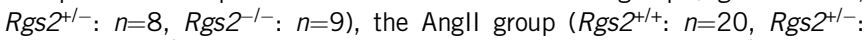

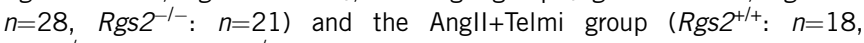
Rgs2 $^{+1-}: n=15$, Rgs2 $\left.^{-1-}: n=15\right) .{ }^{*} P<0.05$.

AngII group in $R g s 2^{-1-}$ mice $(P<0.05)$, whereas no changes in glucose levels were observed. Liver function, as indicated by aspartate aminotransferase, alanine aminotransferase and lactate dehydrogenase levels, was normal (data not shown).

\section{Vascular remodeling}

In the AngII group, $\sim 30-40 \%$ of mice had aortic aneurysms, as shown in Figure 3a. The incidence of aortic aneurysm was not different among Rgs2 genotypes in the AngII group. Rgs $2^{-1-}$ mice treated with AngII+Telmi had a significantly lower rate of aneurysm formation than the AngII group $(P<0.05$, Figure $3 \mathrm{~b})$. In $R g s 2^{+/-}$ mice, the AngII+Telmi group had a lower rate of aneurysm than the AngII group. Moreover, the incidence of aortic aneurysms in $R g s 2^{-1-}$ mice was significantly lower than that in $R g s 2^{+/+}$mice in the AngII+Telmi group $(P<0.05)$.

Next, we compared the diameters of the abdominal aorta (Figure 4). The AngII group showed significantly more enlarged aortic diameters than the control group for all Rgs2 genotypes $\left(R g s 2^{+/+}: P<0.05\right.$, $\left.R g s 2^{+/-}, R g s 2^{-1-}: P<0.001\right)$. Although AngII+Telmi treatment did not reduce blood pressure in any of the genotypes, it significantly reduced enlargement of the aortic diameter compared with the AngII treatment of $R g s 2^{-1-}$ mice $(P<0.01)$. In addition, in $R g s 2^{+/-}$mice the AngII+Telmi treatment tended to reduce the enlargement of the aortic diameter compared with AngII treatment alone.

\section{Oxidative stress in vascular walls}

To assess oxidative stress in the aortic wall, we measured superoxide production and $\mathrm{NAD}(\mathrm{P}) \mathrm{H}$ oxidase activity. Figure $5 \mathrm{~A}$ shows the in situ

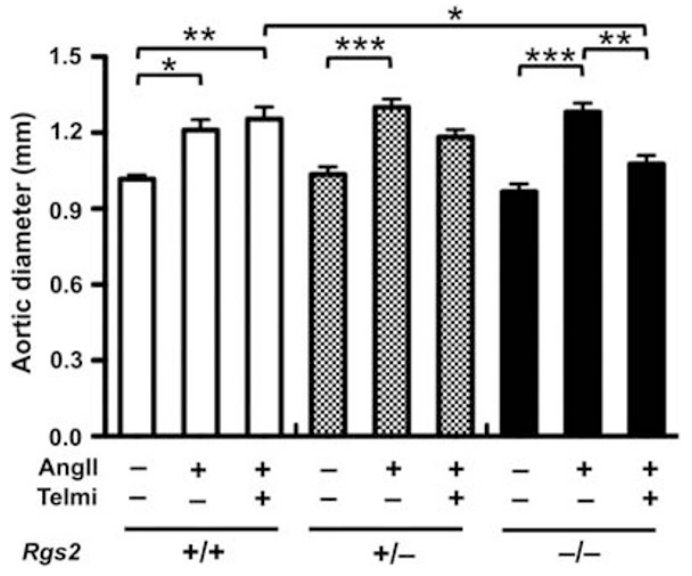

Figure 4 Comparison of abdominal aortic diameters in mice treated with Angll or Angll plus telmisartan. Diameter was measured in the middle of the abdominal aorta between the diaphragm and the renal artery bifurcation, and was compared. Results are expressed as mean \pm s.e.m. in the Control

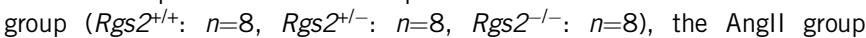
$\left(\operatorname{Rgs}^{+++}: n=12, \operatorname{Rgs}^{+1-}: n=19, \operatorname{Rgs}^{-1-}: n=11\right)$ and the Angll+Telmi

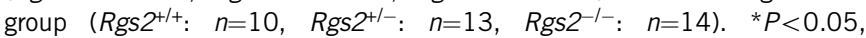
${ }^{* *} P<0.01,{ }^{* * *} P<0.001$

detection of superoxide in the abdominal aorta using dihydroethidium staining in $R g s 2^{-1-}$ mice. The red fluorescence intensity of the aorta in $R g s 2^{-1-}$ mice tended to be more intense in the AngII group and was obviously suppressed in the AngII+Telmi group. Quantitative analysis showed that superoxide production of the aorta in $\mathrm{Rgs}^{-1-}$ mice was significantly decreased in the AngII+Telmi group compared with the AngII group $(P<0.001)$, whereas production in the other Rgs2 genotypes was not statistically different (Figure 5B). Furthermore, the NAD(P)H oxidase activity of aorta in $R g s 2^{-1-}$ mice was also decreased in the AngII+Telmi group compared with the AngII group $(P<0.001$, Figure 5c).

\section{DISCUSSION}

This study showed that the AngII group exhibited higher systolic blood pressure, a higher mortality rate, a higher aortic aneurysm incidence, and a more enlarged aortic diameter than the control group for all Rgs2 genotypes. Interestingly, in $R g s 2^{-1-}$ mice, the AngII+Telmi group showed a significant improvement in the survival rate as well as in the suppression of vascular remodeling compared with the AngII group, although blood pressure was not changed. In parallel with this improvement of vascular phenotypes in $R g s 2^{-/-}$mice, the $\mathrm{NAD}(\mathrm{P}) \mathrm{H}$ oxidase activity and superoxide production of the aorta in $R g s 2^{-1-}$ mice was decreased in the AngII+Telmi group. Thus, lowdose telmisartan could prevent AngII-induced vascular remodeling via the suppression of oxidative stress in the vascular wall of $R g s 2^{-1-}$ mice.

Rgs2 dysfunction is expected to enhance the AngII signaling through $\mathrm{AT}_{1} \mathrm{R}$, leading to blood pressure elevation, atherosclerotic vascular remodeling and organ damage. However, our results did not show significant differences among Rgs2 genotypes in the AngII group, including blood pressure, mortality rate, aneurysmal formation, aortic diameter and aortic oxidative stress (Figures 1-5). The reason for the lack of differences among the Rgs2 genotypes may have been because the concentrations and dosing period of AngII may be excessive and outside the capability of Rgs 2 regulation. Nevertheless, AngII was given in doses sufficient to cause the 


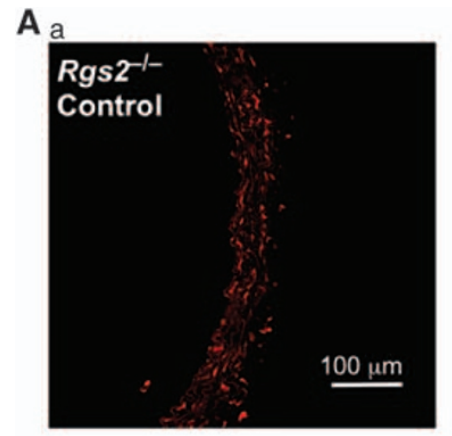

B

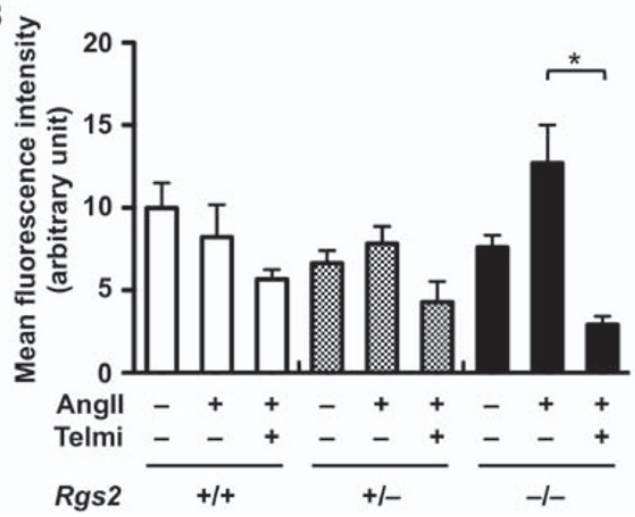

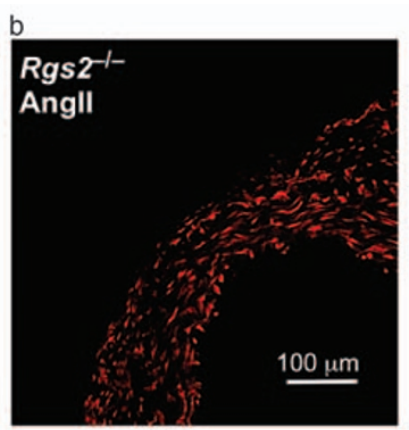

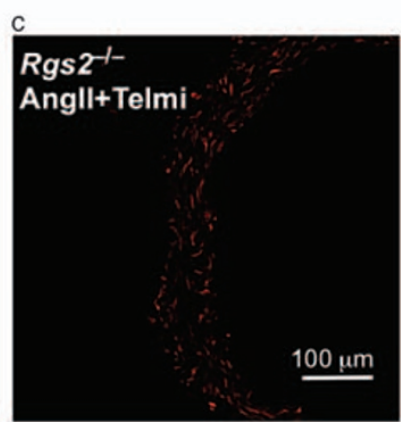

C

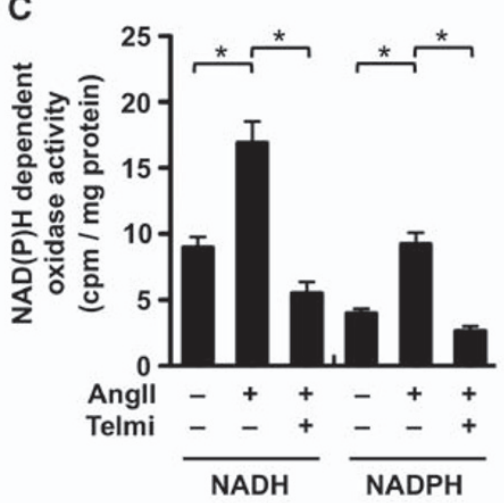

Figure 5 Comparison of oxidative stress in the aortic wall in mice treated with Angll or Angll plus telmisartan. (A), Representative photographs of in situ superoxide production in the aortic wall using dihydroethidium staining in Rgs $2^{-1-}$ mice of the Control group (a), the Angll group (b) and the Angll+Telmi group (c). (B), Quantitative analysis of superoxide production in the aortic wall. For quantification of ethidium fluorescence at the aortic wall, the fluorescence intensity was calculated using the ImageJ software and is expressed in arbitrary units. (C), Effect of telmisartan on NAD(P)H dependent oxidase activity of aorta homogenates using lucigenin-enhanced chemiluminescence in $R g s 2^{-1}$-mice. NAD(P)H oxidase activity was measured as described in Methods section. As a control, NADPH oxidase inhibitor, diphenyleneiodium, reduced NADH and NADPH oxidase activities below measurable limits. Results

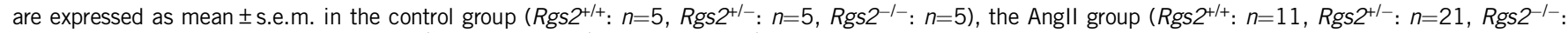
$n=12$ ) and the Angll+Telmi group (Rgs2 ${ }^{+/+}: n=14$, Rgs $^{+1-}: n=15$, Rgs $\left.^{-1-}: n=15\right) .{ }^{*} P<0.001$.

exacerbation of vascular phenotypes in all genotypes under our experimental condition. Thus, we examined the impact of Rgs2 deficiency on the therapeutic effect of low-dose telmisartan in AngII-infused mice.

The most interesting aspect of our study was the observed therapeutic efficacy of telmisartan. Low-dose telmisartan significantly improved survival, inhibited vascular remodeling such as aneurysmal formation and enlargement of aortic diameter, and decreased aortic oxidative stress in $R g s 2^{-1-}$ mice. These effects, mostly observed in the aorta, were independent of blood pressure reduction and were not observed in $\mathrm{Rgs}^{+/+}$mice (Figures 2-5). In $\mathrm{Rgs}^{+/-}$mice, low-dose telmisartan exhibited partial therapeutic effects such as improvement of survival, inhibition of aneurysm formation and reduction of enlarged aortic diameter, although there were no significant differences (Figures 2-4). These Rgs2 deficiency-dependent vascular protective effects of low-dose telmisartan could be explained by the following mechanisms. Some reports have shown that telmisartan and another ARB, valsartan, prevent vascular remodeling through inhibition of oxidative stress, inflammation and degradation of the extracellular matrix independent of their antihypertensive effects. ${ }^{20,24-26}$ Heximer et al. ${ }^{9}$ have reported that responsiveness to another ARB, candesartan, is more sensitive in $R g s 2^{-1-}$ mice than $R g s 2^{+/+}$mice with regard to its antihypertensive and organ protection effects. Thus, vascular protective effects through inhibition of oxidative stress by low-dose ARB may be exaggerated in $R g s 2^{-1-}$ mice as a result of its antagonism for excessive $\mathrm{AT}_{1} \mathrm{R}$ signaling. Moreover, some reports have characterized new functions of telmisartan as a partial agonist for peroxisome proliferator-activated receptors (PPARs). ${ }^{22,23,27}$ Activation of PPAR $\alpha$ by agonists or telmisartan induces an anti-inflammatory response through the repression of nuclear factor- $\kappa \mathrm{B}$ signaling in umbilical vein endothelial cells and aortic smooth muscle cells in vitro ${ }^{27,28}$ and inhibits macrophage infiltration and reduces aortic dilatation in a mouse model of aortic aneurysm. $^{29}$ PPAR $\alpha$ and PPAR $\gamma$ improve lipid and glucose metabolism, respectively. ${ }^{30}$ Low-dose telmisartan in $\mathrm{Rgs}^{-{ }^{-1-}}$ mice improved lipid metabolism but did not affect glucose metabolism, as shown in the Table 1 . Therefore, these protective effects of telmisartan in $R g s 2^{-1-}$ mice might be dependent on the anti-inflammatory response via PPAR $\alpha$ activation, and Rgs 2 deficiency might affect enhancement of the anti-inflammatory effect of telmisartan. Taken together, these results show that the therapeutic effect of lowdose telmisartan might be higher in the aorta of $R g s 2^{-/-}$mice than in that of $\mathrm{Rgs}^{+/+}$mice through both $\mathrm{AT}_{1} \mathrm{R}$ blockade and PPAR $\alpha$ activation.

Hypertension is a major risk factor of cardiovascular disease. Human RGS2 genetic polymorphism is associated with the pathogenesis of hypertension in different races ${ }^{1-14}$ that may result from G $\alpha$ qsignal acceleration by RGS2 dysfunction. Our mouse study did not indicate a relationship between Rgs2 deficiency and the development of atherosclerosis and aneurysm in vivo. Instead, we found that lowdose telmisartan would be beneficial in AngII-induced vascular remodeling, dependent on Rgs2 deficiency and dysfunction. This 
study suggests that ARB might be more useful for protection from cardiovascular events in hypertensive subjects with risk alleles in the RGS2 gene than other antihypertensive drugs. This concept might be applicable for personalized medicine on the basis genetic information.

\section{CONFLICT OF INTEREST}

The authors declare no conflict of interest.

\section{ACKNOWLEDGEMENTS}

We thank Boehringer Ingelheim (Germany) for providing telmisartan. We are grateful to Dr Michael E Mendelsohn (Tufts University School of Medicine) for providing the Rgs2-deficient mice. This work was supported in part by grantsin-aids from the Program for the Promotion of Fundamental Studies in the National Institute of Biochemical Innovation of Japan; the Ministry of Health, Labor and Welfare of Japan; the Ministry of Education, Culture, Sports, Science and Technology of Japan; and the Japan Cardiovascular Research Foundation.

1 Daugherty A, Manning MW, Cassis LA. Angiotensin II promotes atherosclerotic lesions and aneurysms in apolipoprotein E-deficient mice. J Clin Invest 2000; 105 1605-1612.

2 Deng GG, Martin-McNulty B, Sukovich DA, Freay A, Halks-Miller M, Thinnes T, Loskutoff DJ, Carmeliet P, Dole WP, Wang YX. Urokinase-type plasminogen activato plays a critical role in angiotensin II-induced abdominal aortic aneurysm. Circ Res 2003; 92: 510-517.

3 Griendling KK, Minieri CA, Ollerenshaw JD, Alexander RW. Angiotensin II stimulates $\mathrm{NADH}$ and NADPH oxidase activity in cultured vascular smooth muscle cells. Circ Res 1994; 74: 1141-1148.

4 Marchesi C, Paradis P, Schiffrin EL. Role of the renin-angiotensin system in vascular inflammation. Trends Pharmacol Sci 2008; 29: 367-374.

5 Tang KM, Wang GR, Lu P, Karas RH, Aronovitz M, Heximer SP, Kaltenbronn KM, Blumer KJ, Siderovski DP, Zhu Y, Mendelsohn ME. Regulator of G-protein signaling-2 mediates vascular smooth muscle relaxation and blood pressure. Nat Med 2003; 9 : $1506-1512$

6 Sun X, Kaltenbronn KM, Steinberg TH, Blumer KJ. RGS2 is a mediator of nitric oxide action on blood pressure and vasoconstrictor signaling. Mol Pharmacol 2005; 67: 631-639.

7 Calo LA, Pagnin E, Ceolotto G, Davis PA, Schiavo S, Papparella I, Semplicini A, Pessina AC. Silencing regulator of $G$ protein signaling-2 (RGS-2) increases angiotensin II signaling: insights into hypertension from findings in Bartter's/Gitelman's syndromes. J Hypertens 2008; 26: 938-945.

8 Oliveira-Dos-Santos AJ, Matsumoto G, Snow BE, Bai D, Houston FP, Whishaw IQ, Mariathasan S, Sasaki T, Wakeham A, Ohashi PS, Roder JC, Barnes CA, Siderovski DP, Penninger JM. Regulation of T cell activation, anxiety, and male aggression by RGS2. Proc Natl Acad Sci USA 2000; 97: 12272-12277.

9 Heximer SP, Knutsen RH, Sun X, Kaltenbronn KM, Rhee MH, Peng N, Oliveira-dosSantos A, Penninger JM, Muslin AJ, Steinberg TH, Wyss JM, Mecham RP, Blumer KJ. Hypertension and prolonged vasoconstrictor signaling in RGS2-deficient mice. J Clin Invest 2003; 111: 445-452.

10 Hercule HC, Tank J, Plehm R, Wellner M, da Costa Goncalves AC, Gollasch M, Diedrich A, Jordan J, Luft FC, Gross V. Regulator of G protein signalling 2 ameliorates angiotensin II-induced hypertension in mice. Exp Physiol 2007; 92: 1014-1022.

11 Yang J, Kamide K, Kokubo Y, Takiuchi S, Tanaka C, Banno M, Miwa Y, Yoshii M, Horio T, Okayama A, Tomoike H, Kawano Y, Miyata T. Genetic variations of regulator of G-protein signaling 2 in hypertensive patients and in the general population. J Hypertens 2005; 23: 1497-1505.

12 Riddle EL, Rana BK, Murthy KK, Rao F, Eskin E, O'Connor DT, Insel PA. Polymorphisms and haplotypes of the regulator of $G$ protein signaling-2 gene in normotensives and hypertensives. Hypertension 2006; 47: 415-420.
13 Kohara K, Tabara Y, Nakura J, Imai Y, Ohkubo T, Hata A, Soma M, Nakayama T, Umemura S, Hirawa N, Ueshima $\mathrm{H}$, Kita $\mathrm{Y}$, Ogihara T, Katsuya T, Takahashi N, Tokunaga K, Miki T. Identification of hypertension-susceptibility genes and pathways by a systemic multiple candidate gene approach: the millennium genome project for hypertension. Hypertens Res 2008; 31: 203-212.

14 Watanabe Y, Metoki H, Ohkubo T, Katsuya T, Tabara Y, Kikuya M, Hirose T, Sugimoto K, Asayama K, Inoue R, Hara A, Obara T, Nakura J, Kohara K, Totsune K, Ogihara T, Rakugi $\mathrm{H}$, Miki T, Imai Y. Accumulation of common polymorphisms is associated with development of hypertension: a 12-year follow-up from the Ohasama study. Hypertens Res 2010; 33: 129-134.

15 Bodenstein J, Sunahara RK, Neubig RR. N-terminal residues control proteasomal degradation of RGS2, RGS4, and RGS5 in human embryonic kidney 293 cells. Mol Pharmacol 2007; 71: 1040-1050.

16 Gu S, Tirgari S, Heximer SP. The RGS2 gene product from a candidate hypertension allele shows decreased plasma membrane association and inhibition of $\mathrm{Gq}$. $\mathrm{Mol}$ Pharmacol 2008; 73: 1037-1043.

17 Wienen W, Entzeroth M, van Meel JCA, Stangier J, Busch U, Ebner T, Schmid J, Lehmann H, Matzek K, Kempthorne-Rawson J, Gladigau V, Hauel NH. A review on telmisartan: a novel, long-acting angiotensin II-receptor antagonist. Caldiovasc Drug Rev 2000; 18: 127-154.

18 Yusuf S, Teo K, Anderson C, Pogue J, Dyal L, Copland I, Schumacher H, Dagenais G, Sleight P. Effects of the angiotensin-receptor blocker telmisartan on cardiovascular events in high-risk patients intolerant to angiotensin-converting enzyme inhibitors: a randomised controlled trial. Lancet 2008; 372: 1174-1183.

19 Verdecchia P, Angeli F, Mazzotta G, Ambrosio G, Reboldi G. Angiotensin receptor blockers in hypertension. New insights from Japan. Hypertens Res 2010; 33: 394-397.

20 Takaya T, Kawashima S, Shinohara M, Yamashita T, Toh R, Sasaki N, Inoue N, Hirata K, Yokoyama M. Angiotensin II type 1 receptor blocker telmisartan suppresses superoxide production and reduces atherosclerotic lesion formation in apolipoprotein E-deficient mice. Atherosclerosis 2006; 186: 402-410.

21 Terashima M, Ohashi Y, Azumi H, Otsui K, Kaneda H, Awano K, Kobayashi S, Honjo T, Suzuki T, Maeda K, Yokoyama M, Inoue N. Impact of NAD(P)H oxidase-derived reactive oxygen species on coronary arterial remodeling: a comparative intravascular ultrasound and histochemical analysis of atherosclerotic lesions. Circ Cardiovasc Interv 2009; 2: 196-204.

22 Schupp M, Janke J, Clasen R, Unger T, Kintscher U. Angiotensin type 1 receptor blockers induce peroxisome proliferator-activated receptor- $\gamma$ activity. Circulation 2004; 109: 2054-2057.

23 Clemenz M, Frost N, Schupp M, Caron S, Foryst-Ludwig A, Bohm C, Hartge M, Gust R Staels B, Unger T, Kintscher U. Liver-specific peroxisome proliferator-activated receptor $\alpha$ target gene regulation by the angiotensin type 1 receptor blocker telmisartan. Diabetes 2008; 57: 1405-1413.

24 Kaschina E, Schrader F, Sommerfeld M, Kemnitz UR, Grzesiak A, Krikov M, Unger T. Telmisartan prevents aneurysm progression in the rat by inhibiting proteolysis, apoptosis and inflammation. J Hypertens 2008; 26: 2361-2373.

25 Fujiwara Y, Shiraya S, Miyake T, Yamakawa S, Aoki M, Makino H, Nishimura M, Morishita R. Inhibition of experimental abdominal aortic aneurysm in a rat model by the angiotensin receptor blocker valsartan. Int J Mol Med 2008; 22: 703-708.

26 Satoh M, Haruna Y, Fujimoto S, Sasaki T, Kashihara N. Telmisartan improves endothelial dysfunction and renal autoregulation in Dahl salt-sensitive rats. Hypertens Res 2010; 33: 135-142.

27 Nakano A, Hattori Y, Aoki C, Jojima T, Kasai K. Telmisartan inhibits cytokine-induced nuclear factor- $\mathrm{\kappa B}$ activation independently of the peroxisome proliferator-activated receptor- $\gamma$. Hypertens Res 2009; 32: 765-769.

28 Staels B, Koenig W, Habib A, Merval R, Lebret M, Torra IP, Delerive P, Fadel A, Chinetti G, Fruchart JC, Najib J, Maclouf J, Tedgui A. Activation of human aortic smooth-muscle cells is inhibited by PPAR $\alpha$ but not by PPAR $\gamma$ activators. Nature 1998; 393: 790-793.

29 Golledge J, Cullen B, Rush C, Moran CS, Secomb E, Wood F, Daugherty A, Campbell $\mathrm{JH}$, Norman PE. Peroxisome proliferator-activated receptor ligands reduce aortic dilatation in a mouse model of aortic aneurysm. Atherosclerosis 2010; 210: 51-56.

30 Marx N, Duez H, Fruchart JC, Staels B. Peroxisome proliferator-activated receptors and atherogenesis: regulators of gene expression in vascular cells. Circ Res 2004; 94 . 1168-1178. 